\title{
Graphene Nanocomposite Modified Glassy Carbon Electrode: As a Sensing Platform for Simultaneous Determination of Methyldopa and Uric Acid
}

\author{
Kaveh Movlaee ${ }^{1}$, Mohammad Reza Ganjali, ${ }^{1,2}$, Mostafa Aghazadeh $^{3}$, Hadi Beitollahi, \\ Morteza Hosseini ${ }^{5}$, Shirin Shahabi, ${ }^{1}$ Parviz Norouzi ${ }^{1,2}$ \\ ${ }^{1}$ Center of Excellence in Electrochemistry, University of Tehran, Tehran, Iran \\ ${ }^{2}$ Biosensor Research Center, Endocrinology \& Metabolism Molecular-Cellular Sciences Institute, \\ Tehran University of Medical Sciences, Tehran, Iran \\ ${ }^{3}$ NSTRI, P.O. Box 14395-834, Tehran, Iran \\ ${ }^{4}$ Environment Department, Institute of Science and High Technology and Environmental \\ Sciences, Graduate University of Advanced Technology, Kerman, Iran \\ ${ }^{5}$ Department of Life Science Engineering, Faculty of New Sciences \& Technologies, \\ University of Tehran, Tehran, Iran \\ *E-mail: ganjali@khayam.ut.ac.ir
}

doi: $10.20964 / 2017.01 .41$

Received: 7 October 2016 / Accepted: 10 November 2016 / Published: 12 December 2016

$\mathrm{Fe}_{3} \mathrm{O}_{4} @ \mathrm{SiO}_{2} / \mathrm{GO}$ nanocomposite was synthesized and used for surface modification of glassy carbon electrode. This modified electrode was used for electrochemical determination of methyldopa (MD) in the presence of uric acid (UA). Operational parameters such as amount of solution $\mathrm{pH}$ and scan rate which affected the analytical performance of the modified electrode were optimized. The calibration curve for MD was linear in the range of $0.1-400.0 \mu \mathrm{M}$ with the detection limit $(\mathrm{S} / \mathrm{N}=3)$ of $86.0 \mathrm{nM}$. The modified electrode was successfully applied for the determination of MD and UA in some real samples

Keywords: Methyldopa, Uric acid, Nanocomposite, Graphene, Glassy Carbon Electrode

\section{$\underline{\text { FULL TEXT }}$}

(C) 2017 The Authors. Published by ESG (www.electrochemsci.org). This article is an open access article distributed under the terms and conditions of the Creative Commons Attribution license (http://creativecommons.org/licenses/by/4.0/). 